
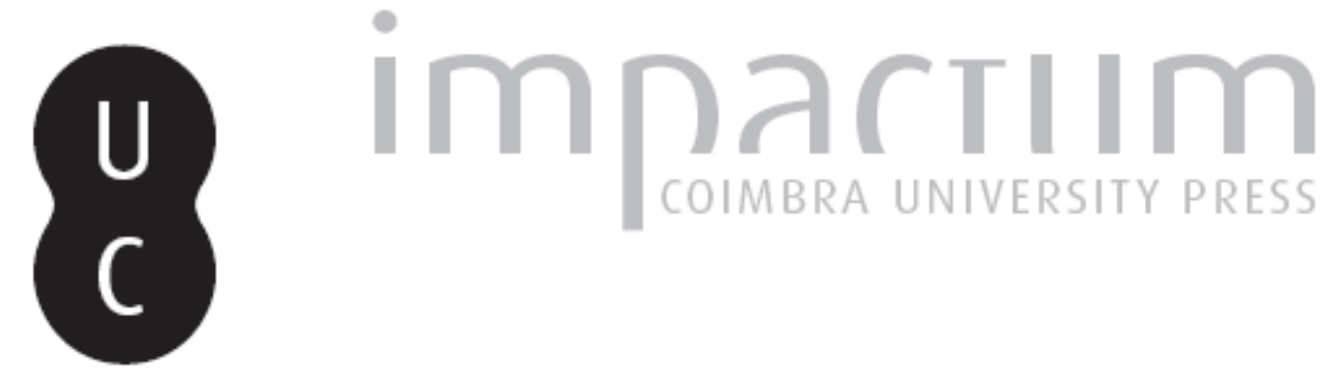

\title{
Três inscrições romanas do concelho de Torres Vedras
}

Autor(es): Mantas, Vasco Gil

Publicado por: Imprensa da Universidade de Coimbra

URL persistente:

URl:http://hdl.handle.net/10316.2/45656

DOI:

DOI:https://dx.doi.org/10.14195/1647-8657_24_6

Accessed : $\quad$ 26-Apr-2023 09:06:01

A navegação consulta e descarregamento dos títulos inseridos nas Bibliotecas Digitais UC Digitalis, UC Pombalina e UC Impactum, pressupõem a aceitação plena e sem reservas dos Termos e Condições de Uso destas Bibliotecas Digitais, disponíveis em https://digitalis.uc.pt/pt-pt/termos.

Conforme exposto nos referidos Termos e Condições de Uso, o descarregamento de títulos de acesso restrito requer uma licença válida de autorização devendo o utilizador aceder ao(s) documento(s) a partir de um endereço de IP da instituição detentora da supramencionada licença.

Ao utilizador é apenas permitido o descarregamento para uso pessoal, pelo que o emprego do(s) título(s) descarregado(s) para outro fim, designadamente comercial, carece de autorização do respetivo autor ou editor da obra.

Na medida em que todas as obras da UC Digitalis se encontram protegidas pelo Código do Direito de Autor e Direitos Conexos e demais legislação aplicável, toda a cópia, parcial ou total, deste documento, nos casos em que é legalmente admitida, deverá conter ou fazer-se acompanhar por este aviso.

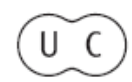


FACULDADE DE LETRAS

INSTITUTO DE ARQUEOLOGIA

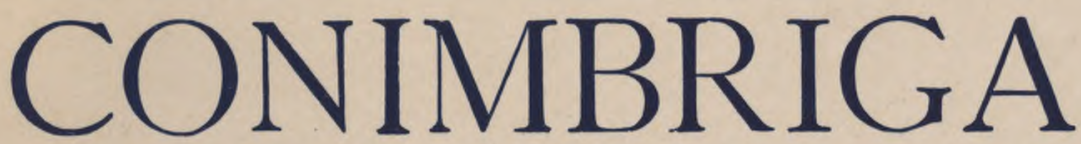

VOLUMEXXIV

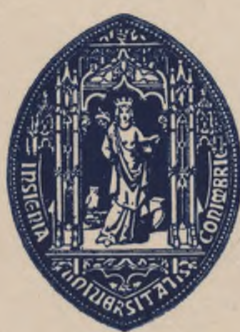

UNIVERSIDADE DE COIMBRA

1985 
Assistente da Faculdade de Letras de Coimbra

TRÊS INSCRIÇÕES ROMANAS DO CONCELHO DE TORRES VEDRAS

«Conimbriga», XXIV (1985). p. 125-149

RESUMO: O autor publica três inscrições funerárias romanas, inéditas, da zona litoral do concelho de Torres Vedras . As epígrafes reñectem quer a existência de um estrato populacional indígena tradicionalista, em vias de romanização, quér a presença de elementos cuja onomástica invulgar permite, tendo em conta a proximidade de Olisipo, abordar o problema das migrações no Império Romano.

RÉSUMÉ: L'auteur publie trois inscriptions funéraires romaines inédites, trouvées dans la zone littorale de la commune de Torres Vedras. Ces inscriptions reflètent tantòt Texistence d'une couche de population indigène traditionnaliste tantôt la présence d'éléments dont 1'onomastique inhabituelle permet d'évoquer, vue la proximité du grand port d 'Olisipo, le problème des migrations dans l'Empire Romain. 
(Página deixada propositadamente em branco) 


\section{TRÊS INSCRIÇÕES ROMANAS DO CONCELHO DE TORRES YEDRAS}

A rápida evolução da paisagem rural em vastas áreas do nosso país, com a consequente destruição e dispersão de vestígios arqueológicos, exige o registo conveniente dos testemunhos ainda existentes e também daqueles que se perderam mas dos quais tenham ficado notícias concretas, trabalho que deve ser completado por uma activa prospecção sistemática e por uma aturada pesquisa bibliográfica. A região de Torres Vedras, que na época romana conheceu uma densa implantação rural, nitidamente relacionada com a proximidade de Olisipo, merece, pelas suas características e riqueza arqueológica, especial atenção. Retomamos neste artigo a publicação do material epigráfico torriense $\left({ }^{\mathrm{x}}\right)$, parte do qual se encontra recolhido no Museu Municipal de Torres Vedras ( ${ }^{2}$ ), com o estudo de três inscrições inéditas provenientes da zona litoral do concelho: uma, da freguesia da Silveira, referida no manuscrito para a segunda edição da parte económica da obra de Madeira Torres

(Ó Agradecemos as informações prestadas e as facilidades de trabalho que nos foram gentilmente concedidas por Leonel Trindade, director do Museu Municipal de Torres Vedras, e pelo P. António Crispim, reverendo pároco de S. Pedro da Cadeira. As fotografias que ilustram este artigo são da autoria de Delfim Ferreira. Fontes abreviadas no texto: Corpus Inscriptionum Latinarum, Berlim (= CIL); Hispania Antiqua Epigraphica, Madrid (= HAE); J. Vives, Inscripciones Latinas de la España Romana, I -11, Barcelona, 1971-1972 (= ILER); R. Hurtado, Corpus Provincial de Inscripciones Latinas, Cáceres, $1977(=$ CPIL $)$.

(2) Vasco Mantas, Inscrições romanas do Museu Municipal dc Torres Vedras, «Conimbriga», XXI, 1982, p. 5-99. 
sobre a vila e o termo de Torres Vedras ${ }^{3}$ ), conservado inédito na Biblioteca Municipal da cidade do Sizandro; duas reutilizadas como soleira na igreja paroquial de S. Pedro da Cadeira.

As inscrições que agora se publicam reforçam os testemunhos da presença romana na zona costeira a norte de Lisboa, reflectindo, uma vez mais, o processo de romanização da região, situada numa d.as áreas lusitanas de maior riqueza epigráfica ${ }^{4}$ ).

\section{1 - QUINTA DA AREIA}

\section{a) Descrição}

Lápida funerária encontrada por meados do século xix num pequeno outeiro denominado Talinto, perto da Quinta da Areia, freguesia da Silveira, Torres Vedras. Em Agosto de 1865, de acordo com o autor do manuscrito para a reedição da memória de Madeira Torres, estava a pedra reutilizada numa porta da casa de António Inácio, no lugar de Guimarães (5). Presentemente desconhecemos o seu paradeiro, não tendo resultado as tentativas efectuadas para a reencontrar. A descrição da epígrafe, ainda que muito resumida, parece aplicável a uma esteia: Achamos estar aberta numa pedra rija em três regras, sendo as duas primeiras em cavado, como em tabuleiros, e com relevos pela parte de cima, tendo apenas quebrado um pedaço numa ponta, que levou parte da primeira letra da primeira regra que era um A. E é deste modo: A PANA/ APANONIS/P $H S \bullet{ }^{6}$ ). A referência aos relevos e aos rebaixos permite relacionar a lápida da Quinta da Areia com outros monumentos da região tórnense, como as esteias da Quinta da Portucheira e da Louriceira, nitidamente pertencentes ao estrato sócio-

(3) M. Madeira Torres, Descripção Historica e Económica da Villa e Termo de Torres Vedras, Coimbra, $1862^{2}$ (edição anotada por J. da Gama Leal e J. de Faro e Vasconcelos).

$\left({ }^{4}\right)$ J. Untermann, Elementos de un Atlas Antroponimico de la Hispania Antigua, Madrid, 1965, p. 18, mapa B.

(5) M. Madeira Torres, Manuscrito, caderno 13, apêndice 19 ao mapa estatístico n. ${ }^{\circ} 1$ (= Torres, Manuscrito).

( ${ }^{6}$ Torres, Manuscrito, caderno 13. 
-cultural indígena $\left({ }^{7}\right)$. Ainda segundo o manuscrito conservado na Biblioteca Municipal de Torres Vedras, a lápida teria sido encontrada entre paredes arruinadas e cobriria uma sepultura de cremação cujo espólio incluía cinzas, cacos de louça muito fina (sigillata? paredes finas?) e bocados de garrafa, sepultura erradamente considerada cristã a partir da ausência de fórmulas funerárias $\left({ }^{8}\right)$.

APANA / APANONIS / F(ilia) $\bullet \mathrm{H}($ ic $) \cdot \mathrm{S}($ ita $) \bullet$

Apaña, filha de Apanão, está aqui sepultada.

\section{b) Bibliografia e variantes}

Inédita.

1.3: P.H.S. (Torres).

\section{c) Comentário}

É extremamente difícil analisar uma epígrafe indirectamente, sobretudo quando a informação disponível é tão escassa como no presente caso. Todavia, a pesquisa documental em bibliotecas e arquivos continua a constituir um importante factor na investigação epigráfica $\left({ }^{9}\right)$, sobretudo em estudos de carácter regional ou local, e sempre que não haja razões para suspeitar dos textos assim recolhidos há que ter em conta as informações que facultam. Neste caso o nosso trabalho é facilitado pela simplicidade do texto e por uma série de pormenores informativos relevantes.

Sobre o aspecto formal da lápida de Apaña pouco podemos dizer, para além do que já referimos quanto à possibilidade de se tratar de um monumento tipológicamente semelhante às rudes esteias indígenas da região, francamente relacionadas com o

(7) Mantas, p. 53-60, n. ${ }^{\circ}$ 9, fot. 10, p. 65-71, n. ${ }^{\circ} 11$, fot. 12.

(8) Torres, Manuscrito, caderno 13.

(9) G. C. Susini, Epigrafia Romana, Roma, 1982, p. 42. 
ambiente cultural predominante em zonas peninsulares menos romanizadas $\left({ }^{10}\right)$. A paginação, necessariamente simples atendendo à brevidade do texto, é correcta, o mesmo sucedendo com a pontuação. O único problema de leitura oferecido pela transcrição da epígrafe encontra-se na 1.3 , onde o manuscrito torriense refere um $\mathrm{P}$, interpretado como sigla de pater. Julgamos tratar-se de um lapso provocado pela má conservação da inscrição, a qual terá levado a considerar o $\mathrm{F}$ de filia como um $\mathrm{P}$, determinando uma tradução aberrante. A fórmula final abreviada $\mathrm{H}($ ¿c).S(¿ta)., embora invulgar nesta região lusitana, ocorrendo apenas em Lisboa (CIL II 237), encontra-se bem documentado na Península Ibérica (ILER 2369-2379), nomeadamente numa inscrição de Castro de Avelãs, típica da rude epigrafia do Noroeste $\left({ }^{\mathrm{n}}\right)$.

A análise antroponímica permite atribuir imediatamente $o$ monumento da Quinta da Areia a um grupo social indígena, pouco romanizado ou conservador, grupo cuja presença nos agri olisiponenses deixou numerosos e significativos testemunhos (12), muito nítidos, por exemplo, no mapa de distribuição das divindades indígenas (13). Apaña, forma feminina de um nome hispânico talvez derivado do radical indo-europeu *ap ou *ab -água, rio $\left({ }^{14}\right)$, é um antropónimo tipicamente lusitano (mapa I), com fraca representação na Gália $\left({ }^{15}\right)$, onde foi registado em Bordéus como marca de cerâmica (CIL XIII 2819c). Apaño pertence ao mesmo grupo e, embora menos vulgar $\left({ }^{16}\right)$, encontra-se na mesma área

(10) A. Garcia Y Bellido, Esculturas Romanas de España y Portugal, I, Madrid, 1949, p. 321-327; A. Tranoy, La Galice Romaine, Paris, 1981, p. 347-350.

(") F. Manuel Alves, Guia Epigráfico do Museu do Abade de Raçal, Bragança, 1975 (reedição), p. 48-49, n. ${ }^{\circ} 13$.

(12) S. Lambino, Les inscriptions de S. Miguel de Odrinhas, "Bulletin des Études Portugaises», XVI, 1952, p. 165-173; Mantas, p. 85-86.

(13) José D'Encarnação, Divindades Indigenas sob o Dominio Romano em Portugal, Lisboa, 1975, p. 310.

(14) M. P. LA P ESA, La Onomástica Personal Pre-Latina de la Antigua Lusitania, Salamanca, 1957, p. 36; M. L. Al вertos, La Onomástica, Personal Primitiva de Hispania Tarraconense y Rética, Salamanca, 1966, p. 1 ( = Alberтоs, Onomástica).

(1̃o) A. Holde R, Alt-Celtischer Sprachschatz, III, Lípsia, 1907, p. 693.

(18) Albertos, Onomástica, p. 1. 
geográfica (mapa I). Entre as numerosas variantes destes antropónimos destacamos a forma sonorizada Abanusja, ainda não referenciada na Lusitânia, e Auanusja, variante gráfica resultante da pronúncia $b / u$ em posição intervocálica $\left({ }^{17}\right)$.

O esquema onomástico utilizado, de tipo peregrino $\left({ }^{18}\right)$, reflecte um estatuto social modesto, confirmado de forma sistemática nas epígrafes onde surgem os antropónimos Apana, Aparto e as suas variantes mais próximas (anexo I), indiscutivelmente representativas do estrato populacional indígena menos romanizado $\left({ }^{19}\right)$.

\section{d) Dotação}

A extrema simplicidade do texto, a ausência de consagração aos deuses Manes, o uso do nominativo e a denominação de tipo peregrino aconselham para esta inscrição uma datação alta, certamente anterior ao final do século $i$, com a qual concorda o ritual e o espólio funerário $\left.{ }^{(20}\right)$.

\section{2 -S. PEDRO DA CADEIRA. Foto 1}

\section{a) Descrição}

Esteia funerária rectangular, de calcário cor de rosa, reutilizada como soleira, juntamente com a lápida $n .^{\circ} 3$, no arco de

$\left({ }^{17}\right)$ J. R. Alija, Españoles por los caminos del Imperio Romano. Estudios epigráfico-onomásticos en torno de Reburrus y Reburrinus, "Cuadernos de Historia de España», XXIX-XXX, 1959, p. 68-69; Albertos, Onomástica, p. 1,42 .

$\left.{ }^{18}\right)$ G. A L Fõ LDy, Notes sur la relation entre le droit dt cité et la nomenclature dans VEmpire romain, «Latomus», XXV, 1, 1966, p. 37, 55-57.

(19) M. L. Albertos, La antroponimia prerromana en la Península Ibérica, «Actas del I Coloquio sobre Lenguas y Culturas Prerromanas de la Península Ibérica», Salamanca, 1976, p. 62-63, 65-67.

(20) Numerosos enterramentos do mesmo tipo, atribuíveis ao século i, foram registados nas grandes necrópoles de Valdoca, em Aljustrel, e de Santo André, perto de Montargil: Jorge de Alarcão/Adília Alarcão, O espolio da necrópole luso-romana de Valdoca, "Conimbriga», V, 1966, p. 7-104; J. R. Viegas/J. S. Nolen/M. F. Días, A necrópole de Santo André, «Conimbriga», XX, 1981, p. 5-180. 
acesso ao baptistério da igreja paroquial de S. Pedro, freguesia de S. Pedro da Cadeira, Torres Vedras. O monumento encontra-se em regular estado de conservação, embora tenha sofrido alguns estragos provocados pela fixação de uma grade, presentemente retirada, estragos que não dificultam a leitura da inscrição. Acusa ainda acentuado desgaste na margem esquerda do campo epigráfico, que preenche a totalidade da face inscrita, bem como no canto superior direito. A permanecer no local onde se encontra, a lápida terá a inscrição gradualmente obliterada pela erosão causada pelos passantes. Não há vestígios de quaisquer elementos decorativos ou de molduração.

Dimensões: 102 X 40 x15(?). Campo epigráfico: 102 X 40.

$D($ is) $[* \mathrm{M}$ (anibus) $\bullet \mathrm{S}$ (aerum)] / SATVRNIA/ AN (norum) $\bullet \mathrm{XXV}$ / H(ic) $\bullet \mathrm{S}$ (ita) - E (st) I ${ }^{5}$ AFRICAN VS / VXORI - MERENTISSIMAE / S $(i t) \cdot T($ ibi $) \cdot \mathrm{T}($ erra $) \cdot h($ evis $) \cdot$

Aos deuses Manes. Satúrnia, de vinte e cinco anos de idade, está aqui sepultada. Africano (mandou fazer este monumento) à sua esposa tão merecedora. Que a terra te seja leve!

Altura das letras: 1. 1: 5,$2 ; 1.2: 6 ; 1.3: 6 ; 1.4: 6 ; 1.5: 6$ $(\mathrm{V}=2) ; 1.6: 6(\mathrm{O}=5,5) ; 1.7 ; 6 ; 1.8: 5,5$. Espaços: e. 1: 11,5; e. $2: 12($ ?); e. $3: 1,5$; e. $4: 2$; e. $5: 2$; e. $6: 2$; e. $7: 3$; e. $8: 2,1$; e. 9: 22 .

\section{b) Bibliografia e variantes}

Inédita.

\section{c) Comentário}

$\mathrm{O}$ ordinator tentou centrar a inscrição, paginada de forma a respeitar quanto possível a regra da integridade das palavras, utilizando um texto clássico muito correcto em que se destacam os nomes da defunta e do dedicante. A epígrafe encontra-se um pouco inclinada sobre a esquerda e o ductus das três primeiras linhas visíveis difere um tanto nas restantes. Atendendo ao seu 
grande desgaste é difícil classificar os sinais empregues na pontuação que, de acordo com o que resta na pedra, parece ter sido bem marcada. É possível que o lapicida tenha recorrido a linhas auxiliares, sobre as quais nada podemos dizer a não ser que se pressentem na regularidade do conjunto. A letra é a do tipo monumental, com nítida influência da escrita actuária, gravada em bisel de forma pouco profunda; ápices relativamente pequenos mas visíveis. Ocorre, com grandes semelhanças, em monumentos de meados do século $\mathrm{n}$, nomeadamente em inscrições norte africanas dos Antoninos (21). Referiremos apenas: S sinuoso, vulgar na capital rústica do tempo de Adriano (22); A muito estreito, com travessão a meia altura; $\mathrm{V}$ de desenho muito irregular; $\mathrm{X}$ deselegante, com ápices perpendiculares; $\mathrm{R}$ com haste oblíqua ligeiramente encurvada e pança fechada; $\mathrm{C}$ em forma de crescente; $\mathrm{M}$ com o ângulo interno bem colocado sobre a linha e hastes exteriores divergentes; travessões muito curtos no T, E, F e L. Destacaremos ainda o pequeno $\mathrm{V}$ da 1.5 e, na 1. 7, o nexo MA, muito vulgar, e o que resta de um E reduzido.

A epígrafe não suscita grandes problemas de leitura. A reutilização da pedra fez com que a 1.1 ficasse quase completamente oculta restando apenas visível o $\mathrm{D}$ da fórmula inicial, que, atendendo à paginação, é certamente D.M.S., invulgar na epigrafia torriense, onde predomina a forma abreviada D.M. $\left.{ }^{23}\right)$. Na 1. 2, a frequência na Hispânia do antropónimo Saturnina favorece uma leitura nesse sentido $\left({ }^{24}\right)$, todavia contrariada pela análise da pedra, que permite reconhecer perfeitamente o ductus do A na última letra do nome da defunta: SATVRNIA. Na 1. 7 há vestígios pouco nítidos do pequeno $\mathrm{E}$ final da palavra MERENTISSIMAE.

Saturnia é nome raríssimo na Península Ibérica, contando apenas com duas referências seguras: D.M.S / Valeria. Sa/turnial I an . XXX I hic . sita . est I s. t. t. /, proveniente de Sevilha (CIL II 1246); Saturnia.v., esta de Salvatierra de Extremadura

(21) R. CAGnat, Cours d'Épigraphie Latine, Paris, 19144, p. 501, pl. X,2,3.

(22) P. Batlle Huguet, Epigrafia Latina, Barcelona, 1946, p. 115.

(28) MANTAS, p. 85; ILER, p. 254-255.

(24) ILER, p. 744-745.

Conimbriga, 24 (1985), 125-149 
(Cáceres, CIL II 1009). Deriva do teónimo Saturnus (20̃), através do sufixo relativamente tardio e pouco utilizado na formação de cognomes ius/ia $\left.{ }^{26}\right)$. É um nome prestigioso, epíteto de divindades como Juno e Vesta $\left({ }^{27}\right)$, atribuído a uma colónia republicana estabelecida no sul da Etrúria (28). O culto de Saturno teve grande popularidade em Roma, conhecendo as Saturnalia, celebradas em Dezembro para relembrar os tempos felizes do reinado igualitário do filho de Urano e de Vesta no Lácio ( ${ }^{29}$ ), extraordinária expansão, apesar do seu carácter perturbador: Saturnalibus tota licentia permittitur ${ }^{30}$ ). Não é impossível que as características especiais deste culto, nomeadamente a nível social, tenham favorecido a grande difusão dos cognomes derivados de Saturnus, em aparente contradição com a importância da divindade (31). Por outro lado, o factor geográfico permite uma explicação para a frequência de tais nomes, através de um processo de interpretatio, como no Norte de África, região onde Saturnus equivale ao púnico Baal ( ${ }^{32}$ ), o que justifica imediatamente o facto de cerca de metade dos testemunhos conhecidos serem africanos ( $\left.{ }^{33}\right)$. É um elemento a ter em conta na epigrafia peninsular pois se uma parte dos antropónimos hispânicos relacionados com Saturnus pertence a indígenas (CIL II $675,771,1071)$, alguns não permitem quaisquer dúvidas quanto à origem africana dos seus detentores: Ulpia. I uniana.et. Antonius.S aturninusl Madaurensis.ann.LX XI.me.vivo.f.c. si qui de meis/super.eos.annos.auserit.post obitum.meum.tamquam..., Mérida (EE VIII 30); Claudio Saturnino Claudius Felijcissimus AferjSaxo Fab...jm.b.m.f, Tarragona [CIL II 4598)|...lann.XXXIII

(25) I. KaJanto, The Latin Cognomina, Helsínquia, 1965, p. 214, 215 ( = KaJAnto, Cognomina $)$.

(26) KaJanto, Cognomina, p. 25-26.

(27) Pauly s Realencyclopadie der Classischen Alter turns wissenchaft, II, AI, Estugarda, 1964, p. $218(=P W)$.

(28) Tito Livio, Hist., XXXIX, 55,9.

(29) $P W$, II, AI, 1964, p. 222-223.

(80) Мастовіо, Sat., I, 7,26.

$\left({ }^{31}\right)$ KaJanto, Cognomina, p. 54.

(32) M. Leglay, Saturne Africain, Paris, 1966, p. 3-10, 477-478. Uma inscrição argelina ostentando o antropónimo Saturbalius não permite qualquer dúvida quanto a esta identificação: KaJANT o, Cognomina, p. 55.

(33) KaJanto, Cognomina, p. 213. 
/G.Blossius Satu;rninus Galeria Napolitanus Afe/r Areniensis incola Balsensis fHi;ae pientissimaelh.s.e.s.t.t.l., Baleizão (Beja, CIL II 105). Outro testemunho significativo é fornecido por uma inscrição votiva de Lugo: Iovi.Optimo.Maximo/Numinibus/Augustorum!

I unoni. Reginae Veneri. Victrici/Africae Caelesti.Frugifero/Augustae. Emeritaelet Laribus.Callaeciarum/Saturninus.A ug.Lib ( $\left.{ }^{34}\right)$. Embora dispersos por toda a Hispânia os elementos do referido grupo antroponímico assumem especial representação em grandes centros administrativos, nomeadamente na capital lusitana, Mérida, e em Tarragona ( ${ }^{35}$ ), o que constitue um dado pertinente quanto a uma possível origem africana. No convento escalabitano foram referenciados em epígrafes de Collipo (S. Sebastião do Freixo, CIL

II 338) e em Conimbriga (CIL II 5240). Lembraremos ainda a consagração a Saturno de dois promontórios peninsulares situados em áreas de influência púnica: o Cabo de Paios, perto de Cartagena, e o Cabo de S. Vicente, no Algarve ( ${ }^{36}$ ). Retomando a análise antroponímica, agora centrada no dedicante, não nos afastamos da problemática que nos tem ocupado. Africanus é um dos muito numerosos cognomes derivados de termos geográficos $\left({ }^{37}\right)$, comum no período republicano e tardo-imperial, segundo Solin ${ }^{38}$ ). Pertence ao grupo mais antigo, formado a partir de nomes de povos através da junção do sufixo anus/na, posteriormente substituído por icus/ca( $\left.{ }^{\beta 9}\right)$, como na inscrição torriense de C. Caecilius Gaetulicus (CIL II 280). Na epigrafía imperial há 121 exemplos de Africanus/na, dos quais 54 se encontram em África; no conjunto do CIL há 99 homens, 7 escravos e libertos e 13 mulheres $\left({ }^{40}\right)$. Estes dados requerem certamente revisão, mas permitem ter uma ideia aproximada da expressão social do

(84) F. Arias Vilas/P. Le Roux/A. Tranoy, Inscriptions Romaines de la Province de Lugo, Paris, 1979, p. 47-48, n. ${ }^{\circ} 23$, pi. IX; Tranoy, p. 310.

(35) L. Garcia Iglesias, Epigrafia Romana de Augusta Emerita, II, Madrid, 1973, p. 1027; G. Alfoldy, Die Rõmischen Inschriften von Tarraco, I, Berlim, 1975, p. 496.

(36) Ртоlomeu, II, 6, 14; Avieno, Ora Mar., 215-216.

(37) KaJAnto, Cognomina, p. 43.

(38) H. Solın, Die Innere Chronologie der Rõmischen Cognomens, «Actes du Colloque International sur l'Onomastique Latine», Paris, 1977, p. 106.

(39) KaJan T o, Cognomina, p. 52.

$\left({ }^{40}\right)$ Kajanto, Cognomina, p. 205. 
cognome, usado por alguns cônsules como T. Sextius Africanus, colega de Trajano no consulado em $112\left({ }^{41}\right)$. Na Península Ibérica conta com modesta representação, cuja distribuição geográfica, periférica (mapa II), concorda perfeitamente com uma origem não local. Os testemunhos conhecidos são provenientes de Górdova (CIL II 2195), Sevilha (CIL II 5396), Denia (CIL II 5969), Palencia (ILER 804) e Ujo (Oviedo, ILER 900, 5676). Uma breve análise dos mesmos permite verificar que se trata de indivíduos muito romanizados (anexo II), mesmo quando, como no caso do dedicante das duas inscrições de Ujo $\left({ }^{42}\right)$, ou ainda na de Palencia (ILER 804), se pode admitir uma origem hispânica. Um cognome aparentado, Afer/fra $\left({ }^{43}\right)$, tem razoável frequência na Península $\left({ }^{44}\right)$, tendo sido registado, na Lusitânia, em Lisboa (CIL II 201), Ammaia (Marvão, CIL II 160), Évora (CIL II 5098), Talavera la Vieja (CIL II 934), Trujillo (CIL II 658, 685, 5283) e, na zona rural do município olisiponense, em S. Miguel de Odrinhas (ILER 3339).

A análise antroponímica, se não permite considerar automaticamente Saturnia e Africanus como estranhos ao fundo populacional indígena, pois podemos estar perante mais um exemplo da utilização por peregrinos de nomes romanos isolados, os nuda nomina ( ${ }^{45}$ ), também nada lhe opõe. Assim, tendo em conta os testemunhos hispânicos dos antropónimos, a presença no termo torriense de elementos directa ou indirectamente relacionados com o Norte de África, como o já referido C. Caecilius Gaetulicus da Quinta de S. Gião $\left({ }^{46}\right)$, e a influência regional de disipo, principal porto da Lusitânia a partir de meados do século i $\left({ }^{47}\right)$, julgamos poder atribuir ao casal referido nesta inscrição uma presu-

(41) PW, I, 1, 1958, p. 716.

(42) P. LE Roux, VArmée Romaine et VOrganisation des Provinces Ibériques d'Auguste à CInvasion de 409, Paris, 1982, p. 247-249.

(43) KaJanto, Cognomina, p. 205.

(44) CIL II, p. 1077; ILER, p. 205.

(45) J. P. Rey-Coquais, Onomastique et histoire de la Syrie gréco-romaine, «Actes du VII ${ }^{e}$ Congrés International d'Épigraphie Grecque et Latine», Bucareste-Paris, 1979, p. 177.

(46) Mantas, p. 17-21, n. ${ }^{\circ}$ 2, fot. 3.

(47) Jorge de Alarcão, Portugal Romano, Lisboa, 1983a, p. 160-161, 164 (= AlarCão, Portugal). 
mível origem africana. Quanto ao seu estatuto social, dado que a epígrafe é anterior à redução do cognome a nome único $\left({ }^{48}\right)$, era certamente modesto, talvez mesmo servil $\left({ }^{49}\right)$, embora esta última possibilidade seja aparentemente contrariada pelo valor jurídico do termo uxor $\left({ }^{50}\right)$.

A expressão uxori merentissimae é rara na epigrafia peninsular e, para além de apoiar uma datação relativamente avançada ( $\left.{ }^{51}\right)$, constitue um factor suplementar favorável a uma situação social modesta, sugerida pelas duas referências que conseguimos registar, em Mérida (ILER 4386) e em Évora ( ${ }^{52}$ ). Tais expressões, estereotipadas, nem por isso deixavam de corresponder, na maioria dos casos, a sentimentos verdadeiros ( ${ }^{53}$ ), pelo que só os preconceitos e as dúvidas da nossa própria civilização justificam a ironia com que por vezes são consideradas. A fórmula que encerra a inscrição é das mais vulgares da epigrafia romana.

\section{d) Datação}

A análise paleográfica da epígrafe, a consagração aos deuses Manes, o esquema geral do texto, a utilização de um adjectivo para qualificar uxor, são elementos que permitem atribuir esta inscrição a meados do século $\mathrm{n}$.

\section{3 - S. PEDRO DA CADEIRA. Foto 2}

\section{a) Descrição}

Esteia funerária rectangular, de calcário cor de rosa, reutilizada com a epígrafe $n .^{\circ} 2$ como soleira no arco de acesso ao baptistério da igreja paroquial de S. Pedro, freguesia de S. Pedro

(48) SUSINI, p. 106.

(49) J. Baumgart, Die Rõmischen Sklavennamen, Breslau, 1936, p. 50.

(50) H. Thylander, Étude sur V Épigraphie Latine, Lund, 1952, p. 216.

(51) L. Curchin, Familial Epithets in the Epigraphy of Roman Spain, «Mélanges Étienne Gareau», Ottawa, 1982, p. 179.

(52) José D'EnCARnaÇão, Notas sobre epigrafia romana de Evora, «Humanitas», XXIX-XXX, 1977-1978, p. 83-85, n. ${ }^{\circ} 4$.

(53) Curchin, p. 181-182. 
da Cadeira, Torres Vedras. O aspecto geral do monumento é em tudo idéntico ao de Saturnia; algumas pequenas falhas na margem direita e as cavidades de fixação de uma grade não prejudicam a leitura da inscrição, bastante dificultada, por outro lado, pelo acentuado desgaste da pedra, o qual não deixará de se agravar a menos que a lápida seja rapidamente removida para local menos exposto. O campo epigráfico ocupa toda a face da estela, aparentemente desprovida de quaisquer ornatos ou molduras.

Dimensões: 117 X 39 X14(?). Campo epigráfico: 117 X 39 .

\section{$\mathrm{D}$ (is) M (anibus) / M (arco) ll(lio) MORPHO / AN (norum) XXVI / / Q(uintus) B(ovius) CALAMON P ater) /5 FILIO POSVIT / DEDI- CAVIT (que).}

Aos deuses Manes. A Marco Júlio Morfo, de vinte e seis anos de idade. Quinto Bóvio Calamão colocou e dedicou ao filho (este monumento).

Altura das letras: 1. 1: 4,5; $\quad 1.2: 3,8 ; 1.3: 3,8 \quad(1=3,1)$; 1. 4: $4(\mathrm{C}=4,4) ; 1.5: 3,9\left(1 .^{\circ} \mathrm{O}=3,5 ; \quad 2 .^{\circ} \mathrm{O}-3 ; \quad \mathrm{T}=3,1\right)$; I. 6: $3,5(\mathrm{D}=3,8)$. Espaços: e. $1: 13,5 ;$ e. $2: 1,8 ; \quad$ e. $3: 1,5$; e. $4: 1,5 ;$ e. $5: 2,5 ; \quad$ e. $6: 1,2 ;$ e. $7: 71$.

\section{b) Bibliografia e variantes}

Inédita.

\section{c) Comentário}

O trabalho do lapidarius que gravou a epígrafe não corresponde à qualidade da paginação, que desdobra o texto de forma muito correcta, embora tenha havido uma certa preocupação em conseguir alinhamento à esquerda e em alternar a extensão das linhas. Todavia, a irregularidade do ductus é geral, evidenciando-se nas diferenças do traçado, dimensões e afastamento das letras, bem como no ondulado da última linha. A gravação é pouco profunda, de incisão triangular; a letra é do tipo monumental, de desenho medíocre, com alguma influência da escrita actuária; os 
ápices, embora pouco marcados, são nítidos. Não há sinais visíveis de pontuação. No conjunto, a letra patente na inscrição corresponde a um alfabeto largamente utilizado no século n: o D deselegante, o $\mathrm{M}$ derivado de uma forma cursiva ( ${ }^{54}$ ), os $\mathrm{T}, \mathrm{F}, \mathrm{L}$ e $\mathrm{E}$, de travessões muito curtos, quase cursivos, são característicos dessa época. Destacaremos ainda o aspecto lunar do $\mathrm{C}$, o $\mathrm{P}$ aberto e a partir do qual se obteve o $\mathrm{R}$ e o desenho relativamente clássico do B e do O. O nexo AM, na 1. 4, é muito frequente.

A leitura da epígrafe oferece alguns problemas de difícil solução. $\mathrm{Na} 1.2$ a sigla do preñóme Marcus lê-se com razoável nitidez, sem permitir dúvidas; segue-se a indicação abreviada do gentilicio, prática referenciada noutras inscrições torrienses ${ }^{(55)}$. A dificuldade maior reside, todavia, na 1. 4, preenchida na quase totalidade pelos tria nomina do dedicante. O preñóme Quintus está representado por um Q Gustosamente visível, a que se segue um B, sigla de um gentilicio que, por razões que referiremos adiante, julgamos ser Bovius. Mais difícil é a leitura do cognome, para o qual durante algum tempo considerámos possível qualquer coisa como Caimo, variante do nome indígena Caeno $\left({ }^{56}\right)$, atestada apenas numa obscura inscrição de U1 $\left.{ }^{57}\right)$, hoje perdida, e talvez no hidrónimo Caima, afluente do Vouga. A rigorosa análise da pedra não favorece tal interpretação: se as primeiras letras não constituem problema, não obstante o curioso ductus do A, segue-se um $\mathrm{L}$ cujo travessão desapareceu e o nexo AM, extremamente difícil de perceber, como todos os travessões da letra $\mathrm{A}$; a seguir temos um $\mathrm{O}$ indiscutível e o que pensamos ser o que resta de um $\mathrm{N}$. Podemos assim restituir, com algumas reservas, o cognome CALAMON. A 1. 4 termina com o que nos parece um $\mathrm{P}$, sigla da palavra pater. $\mathrm{Na} 1.5$ o $\mathrm{P}$ e o $\mathrm{O}$ de POSVIT encontram-se muito prejudicados pela má conservação do monumento.

A análise antroponímica desta inscrição revela-se plena de interesse, pois permite abordar vários problemas importantes.

(54) Cagnat, p. 18-19.

(55) Cagnat, p. 51-52; Mantas, 32-33, 35-36.

(56) Untermann, p. 79-80, mapa 22; Albertos, Onomástica, p. 68-69.

$\left.{ }^{57}\right)$ D. A. Souto, Subsidios para urna Carta Arqueológica do Distrito de Aveiro no Período da Romanização, Aveiro, 1958, p. 22-23. 
M. Iulius Morphus ostenta o gentilicio mais vulgar da epigrafia hispano-romana ${ }^{58}$ ), inclusive na zona de Lisboa, reflectindo certamente laços de clientela estabelecidos na fase inicial do Império $\left({ }^{59}\right)$. $\mathrm{Na}$ região torriense conhecem-se dois outros M. Iulii: M. Iulius Crescens e M. Iulius Gallus, cidadãos da tribo Galéria, o primeiro referido num pedestal funerário de Torres Vedras $\left({ }^{60}\right)$, o segundo numa cupa da Azueira (CIL II 302). Morphus é um raríssimo cognome de origem grega $\left({ }^{61}\right)$, exclusivamente referenciado, com predomínio da forma feminina, em inscrições italianas de Pavia $\{C I L$ V 3027) e de Roma \{CIL VI 9690, 15854, 35907). Ainda de Roma, mas por via literária, conhecemos um Morphos que se celebrizou como pantomina no século n $\left.{ }^{62}\right)$. O cognome exprime uma clara relação com a teogonia grega, pois deriva de Morpheus, filho de Hipnos, deus do sono, e irmão de dois outros génios, Ikelos e Phantasos (63). Em Portugal, Hipnus foi registado como nome próprio em Tróia, importante povoação industrial romana no estuário do Sado, naturalmente propícia à onomástica grega $\left({ }^{64}\right)$. Morpheus, como se depreende da seguinte passagem de Ovídio em que se refere a sua acção, presidia aos sonhos: Excitat artificem simulatoremque figurae Morphea $\left({ }^{65}\right)$. O sentido religioso do antropónimo é ainda reforçado pelo facto de Morpho ocorrer como epíteto de Afrodite na Lacedemónia ( $\left.{ }^{66}\right)$. Um cognome aparentado, Callimorphus, embora desconhecido na Península Ibérica tem importante representação no Ocidente $\left({ }^{67}\right)$. Quanto à denominação do dedicante, admitindo a leitura proposta, não é menos destituída

(58) CIL II, p. 1064-1065; ILER, p. 705-708.

(59) R. KNAPP, The Origins of Provincial Prosopography in the West, «Ancient Society», 9, 1978, p. 199-200, 214.

${ }^{(60)}$ Mantas, p. 27-32, n. ${ }^{\circ}$ 4, fot. 5.

(61) PW, XVI, 1,1965, p. 313; H. Solin, Die Griechischen Personennamen in Rom, III, Berlim, 1982, p. 1245, 1351.

(62) Galeno, XIV, 635.

(63) $P W$, XVI, 1, 1965, p. 313.

(64) J. L. Vasconcelos, As Religiões da Lusitânia, III, Lisboa, 1913, p. 370 .

(65) Ovídio, Met., 633-635.

(66) Thesaurus Graecae Linguae, VI, Graz, 1954², p. 1209 (= TGL).

$\left({ }^{67}\right)$ Thesaurus Linguae Latinae, II, Lipsia, 1909, p. 90 (= TLL). 
de interesse. O preñóme Quintus, de longínqua origem numeral (68), é muito vulgar na região lisboeta $\left({ }^{69}\right)$. Apesar do número de prenomes utilizados ter sido limitado, uma análise da forma como se combinavam com o gentilicio e da repartição e frequência geográfica de algumas dessas combinações permite obter informações significativas quanto à estrutura social urbana ou rural $\left({ }^{70}\right)$. Esta observação resulta igualmente válida para a região tórnense. Com efeito, o preñóme Quintus é o único que se encontra no epitáfio de Q. Bovius Atimetio Victor, em que a sigla B surge como indicação inequívoca do gentilicio Bovius $\left.{ }^{71}\right)$, conferindo assim um destaque especial aos $Q$. Bovii, grupo a que julgamos pertencer Q.B.Calamon. Os testemunhos epigráficos da gens Bovia não são numerosos, quer na Península (72), quer nas restantes regiões do Império, contribuindo a Itália com a maior parte deles (CIL VI 13629, 13630, 13631; CIL IX 1048, 1321, 5420, 5469; CIL X 129, 1685, 1886, 2172, 2711; CIL XI 6700136, 670156). As poucas referências lusitanas concentram-se na zona ocidental da província: Q.Bovio Atim/etioni Victori/Q.B.Marciani/ann.LXXIQ.B.Potitus/patri optumo, Torres Vedras (73); L.Bovius Iuli/anus an.LXXI, Oeiras (CIL II 5011); D.M.S./G.IulilMaterni ann.LXIIL/Bovia Ma/terna et Iulia Ma/xima patri piissimolf.c./curant[e]IIulio Dex/tro liber/to ob merita/patroni, Coimbra (CIL II 378); M[...] Bov[ius].../M $f$ Pa[...]lanno $\left[\right.$....]/Valeria[...]/na uxor f.c, Barbacena ( $\left.{ }^{74}\right)$. Segundo Schulze o gentilicio, que talvez derive do indo-europeu *gwou $\left({ }^{75}\right)$, terá origem etrusca $\left({ }^{76}\right)$. Na Hispânia ocorre por vezes como nome

$\left({ }^{*}\right)$ Cagnat, p. 43.

(®9) A. Vieira da Silva, Epigrafia de Olisipo, Lisboa, 1944, p. 276-283.

( $\left.{ }^{70}\right)$ R. ETIENNE, Senateurs originaires de la province de Lusitanie, «Tituli», 5, 1982, p. 521-529.

(71) Mantas, p. 35-42, n. ${ }^{\circ} 6$, fot. 7 .

(72) CIL II, p. 1057 ; ILER, p. 670.

(73) Mantas, p. $35-42$, n. ${ }^{\circ} 6$, fot. 7.

(74) H. S. Louro, Inscrições romanas de Barbacená, «Actas e Memórias do I Congresso Nacional de Arqueologia», II, Lisboa, 1970, p. 106 (corrigida).

(75) M. L. Al bertos, Nuevos antropónimos hispánicos, «Emerita», XXXII, 2, 1964, p. 213 (= Al в ER tos, Antropónimos).

(76) W. ScHULZE, Zur Geschichte Lateinischer Eigennamen, Berlim, 1966², p. 234 . 
único em ambientes célticos, como provável latinização de um nome indígena $\left({ }^{77}\right)$, possibilidade que se verifica numa estela tórnense proveniente da Louriceira $\left({ }^{78}\right)$. Calamón é um nome próprio grego, muito raro $\left({ }^{79}\right)$, ausente dos índices do $\mathrm{C} / \mathrm{L}$, aqui utilizado como cognome, de acordo com a prática observada na formação dos nomes dos libertos e de quem recebia a cidadania romana $\left({ }^{80}\right)$. Não é de excluir a hipótese de se tratar de mais um termo geográfico transformado em antropónimo, pois Kalamon era o nome de um monte situado a sul de Seleucia, na Síria ( $\left.{ }^{81}\right)$, e Calamón a designação de uma mutatio não identificada, algures na costa palestiniana entre Ptolomais e Sicamenos ( ${ }^{82}$ ). Ainda no Levante, e por referências da Notitia Dignitatum, conhecemos duas estações militares Calamona, uma na Palestina ( ${ }^{83}$ ), outra na Fenícia $\left({ }^{84}\right)$, denominação que parece regularmente derivada de Calamón ( ${ }^{85}$ ). Sem que esqueçamos o controverso significado da onomástica grega, em grande parte artificial no ocidente da Romania ( $\left.{ }^{86}\right)$, a raridade dos cognomes em causa e as relações que permitem estabelecer, sugerem francamente uma origem helénica, talvez mesmo oriental. Quanto ao estatuto social de Morphus e de Calamón não erraremos se os considerarmos cidadãos romanos de direito latino ${ }^{87}$ ), libertos, como os gentilicios diferentes do pai e do filho e os cognomes gregos insinuam, embora a onomástica

(77) Albertos, Antropônimos, XXXII, 2, 1964, p. 231.

$\left(^{78}\right)$ Mantas, p. 65-71, n. ${ }^{\circ} \mathbf{1 1}$, fot. 12.

(79) TGL, V, $1954^{2}$, p. 868.

${ }^{80}$ Cagnat, p. 77-82.

(81) $P W, \mathrm{X}, 2,1965$, p. 1538.

(82) $P W$, III, 1, 1958, p. 1329.

(83) Not. Dign. Or., XXXIV, 43.

H Not. Dign. Or., XXXII, 11. -616 .

(85) C. Bémont, Liciniana Officina, «Latomus», XXVII, 3, 1968, p. 610-

(86) Thylander^ p. 122; P. Petit. La Paix Romaine, Paris, 1967, p. 258-259; R. ÉtIENne, Remarques sur Vonomastique romaine d'Espagne, «Actes du Golloque International sur 1'Onomastique Latine», Paris, 1977, p. 291-292.

$\left({ }^{87}\right)$ Alfòldy, Notes, p. 55-57; I. KaJanto, The Significance of Non-Latin Cognomina, «Latomus», XXVII, 3, 1968, p. 519-529 (= KaJanto, Non-Latin Cognomina). 
grega nem sempre implique uma origem servil ( $\left.{ }^{88}\right)$. Na verdade, a análise das inscrições hispânicas em que, como no presente caso, se encontram nomina diferentes na mesma família, permite verificar que estas se incluem maioritariamente num ambiente de libertos, constatando-se que em oito dos doze testemunhos indiciados no $C I L$ ocorrem antropónimos gregos (89), facto que nos parece significativo em relação à opinião que exprimimos. É certo que em casos especiais a anomalia pode resultar da adopção do gentilicio da mãe $\left.{ }^{90}\right)$, como poderá ter sucedido numa família de Coimbra em que as filhas do cidadão G. Iulius Maternus se chamavam Bovia Materna e Iulia Maxima (CIL II 378), curiosamente os mesmos gentilicios presentes na inscrição de S. Pedro da Cadeira. $\mathrm{Na}$ epígrafe torriense, porém, a explicação possível reside na dependência de patronos diferentes, um pertencente à gens Iulia, outro à gens Bovia, indício seguro de um nascimento ilegítimo $\left({ }^{91}\right)$.

A antroponímia grega é frequente nas inscrições luso-romanas, em especial a sul do Tejo $\left({ }^{92}\right)$, onde parece quase completamente alheia ao mundo indígena ${ }^{\left({ }^{9}\right)}$ ). A sua presença na região de Torres Vedras, outrora integrada nos limites do município olisiponense, reflecte a influência do principal porto lusitano sobre o território rural adjacente, cuja economia controlava. Lisboa concorre com a maior concentração de antropónimos gregos nas epígrafes romanas do território português ${ }^{94}$ ), facto que corresponde perfeitamente

(88) L. F. Sмітн, The Significance of Greek Cognomina in Italy, «Classical Philology», 29, 1934, p. 145-147; ThyLander, p. 143-149.

H CIL II, p. 1199.

(90) G. BARbieri, SulVonomástica delle famiglie senatorie dei primi secoli deWImpero, «Actes du Colloque International sur 1'Onomastique Latine», Paris, 1977, p. 179-180.

(91) CAgnat, p. 67, 72, 85-86.

(92) F. BANdeira Ferreira, Varia epigraphica, «Revista da Faculdade de Letras», III, 2, 1958, p. 158-162.

(93) JosÉ D'EnCARnaÇão, Épigraphie funéraire du Conventus Pacensis (Lusitanie). Un essai de distribution géo-sociologique des types de monuments, «Actes du Colloque sur l'Épigraphie Hispanique: Problémes de Méthode et d'Édition», Paris, 1984, p. 298-299 (= EnCarnação, Épigraphie).

${ }^{(94)}$ Vieira da Silva, p. 276-283. A população dos portos itálicos sob o Império parece ter sido em grande parte grego-oriental: THYLANDER, p. 183. 
ao modelo de repartição observado noutras regiões da Península, condicionado por actividades económicas e administrativas $\left({ }^{95}\right)$. Urna das inscrições lisboetas, consagrada a Esculápio pelos Augustais M.Afranius Euporio e L.Fabius Daphnus (CIL II 175), poderá, atendendo ao cognome deste último, indicar a presença de elementos levantinos helénicos. Com efeito, o cognome Daphnus, que na Península Ibérica ocorre quase exclusivamente em grandes centros portuários, como Tarragona (ILER 4068, 4081), Cartagena (ILER 6151) e Almeria (CIL II 5489), talvez se relacione com Daphne, importante subúrbio de Antioquia ( $\left.{ }^{96}\right)$. Todavia, se as relações comerciais mais tardias de Olisipo com o Oriente estão comprovadas $\left({ }^{97}\right)$, é preciso interpretar muito cautelosamente dados deste tipo, sobretudo enquanto não existir um estudo sistemático da antroponímia grega registada nas inscrições romanas do território português.

A concretização da filiação através da palavra $P$ (ater) justifica-se por serem diferentes os gentilicios usados pelo pai e pelo filho, embora surja por vezes de forma mais ou menos redundante, como numa epígrafe de Leiria (CIL II 342). A expressão posuit dedicavit, que concorda perfeitamente com o tipo de monumento consagrado a Morphus $\left({ }^{98}\right)$, é pouco vulgar, não constando dos principais repertórios epigráficos peninsulares (").

(95) M. R. Oliete/J. S. Yanguas, Griegos en la Bélica a través de la; epigrafia latina, "Actas del I Congreso de Historia de Andalucía», Córdova, 1978, p. 239-246; A. Vilas/Le Roux/A. Tranoy, p. 120; G. Forni, La populazione di Augusta Emerita, «Homenaje a Saenz de Buruaga», Madrid, 1982, p. 77-78.

(96) J. C. Sournia/M. Sournia, VOrient des Premiers Chretiens, Paris, 1966, p. 32-33.

$\left({ }^{97}\right)$ M. Giachero, Edictum Diocletiani et Collegarum de Pretiis Rerum Venalium in Integra Restitutum e Latinis Graecisque Fragmentis, I, Génova, 1974, p. 310; L. G. Moreno, Colonias de comerciantes orientales en la Peninsula Ibérica. Siglos V-VII, «Habis», 3, 1973, p. 148-149; Alarcão .Portugal, p. 162.

$\left.{ }^{98}\right)$ J. N. Bonneville, Le suport monumental des inscriptions. Terminologie et analyse, «Actes du Colloque sur PÉpigraphie Hispanique: Problémes de Méthode et d'Édition», Paris, 1984, p. 129, 136.

(") CIL II, p. 1177, 1194; Huguet, p. 193-195. 
Junto à povoação de S. Pedro da Cadeira, outrora denominada Rendide, encontraram-se, no sítio dos Formigais, vestígios de construções romanas, nomeadamente tégulas. A observação aérea do local, que efectuámos em Setembro de 1980, revelou alguns indícios prometedores, sendo possível que as duas esteias conservadas na igreja paroquial daí provenham. Tudo leva a crer tratar-se dos restos de mais uma das tão numerosas quão mal conhecidas villae da região torriense.

\section{d) Datação}

O uso do dativo, a consagração aos deuses Manes abreviada, o desenvolvimento do texto e as características da escrita evidenciadas pela análise paleográfica levam-nos a considerar esta inscrição, tal como a anterior, de meados do século $\mathrm{n}$, tanto mais que tipológicamente se assemelham.

\section{CONCLUSÕES}

Os dados fornecidos pelas epígrafes estudadas neste artigo, reforçando indícios já verificados, integram-se perfeitamente no conjunto de informações facultadas pelas cerca de duas dúzias de inscrições conhecidas no aro torriense, as quais, apesar do seu limitado número, permitem esboçar um quadro da estrutura da população regional e da evolução da romanização nos séculos $\mathrm{i}$ e ii. A natureza céltica ou celtizada do fundo populacional indígena e a permanência de modelos tradicionais reflecte-se na inscrição de Apana (n. ${ }^{\circ}$ ), enquanto as estelas de Saturnia (n. $\left.{ }^{\circ} 2\right)$ e de Morphus (n. ${ }^{\circ}$ ) permitem abordar o problema da influência cultural mediterrânica e também, segundo cremos, a questão das migrações internas no Império, admitindo a validade dos dados onomásticos como indicadores da origem étnica e geográfica $\left({ }^{10}\right)$. As relações da região torriense com o Norte de África e com o Oriente devem ser consideradas, naturalmente, de forma cautelosa

(iº) Thylander, p. 157-159; Kajanto, Non-Latin Cognomina, p. 517-534 . 
e no âmbito da função de Olisipo como centro portuário e da sua influência cultural e económica sobre os agri dependentes (101). Uma das inscrições de S. Pedro da Cadeira destaca novamente a importância local dos Q.Bovii (n. ${ }^{\circ}$ 3), inserindo-se no ambiente sócio-cultural que lhes parece próprio nesta zona, o dos libertos. Mais modesto, talvez servil, parece ter sido o estatuto social de Saturnia e de Africanus (n. ${ }^{\circ}$ 2). Quanto ao desaparecido monumento da Quinta da Areia (n. ${ }^{\circ}$ 1), mais antigo que os anteriores, refere peregrinos em vias de romanização. Temos assim elementos indígenas e outros directa ou indirectamente relacionados com a colonização romana, alheios, de qualquer forma, aos costumes tradicionais da região, a menos que queiramos considerar o tipo de monumento utilizado - a esteia - como uma influência do meio. Todavia, se a esteia prevalece, também aqui, como o tipo de monumento funerário preferido pelos peregrinos $\left({ }^{102}\right)$, o material em que foram executadas as epígrafes de S. Pedro da Cadeira, proveniente da zona de Sintra, não corresponde ao que habitualmente se utilizou na região. Sem excluir a hipótese de se tratar de obras de uma oficina local $\left({ }^{103}\right)$, aliás modestas não obstante o rigor clássico dos textos, parece ter havido deliberada intenção de marcar uma diferença, tanto mais que as estelas de S. Pedro da Cadeira diferem acentuadamente das esteias de tradição indígena. Por outro lado, em Astorga, uma esteia com o epitáfio redigido em grego demonstra que era possível optar, num ambiente urbano perfeitamente romanizado, por um tipo de monumento com especial representação no meio rural indígena $\left({ }^{104}\right)$, aconselhando prudência nas generalizações e pondo em destaque, uma vez mais, a permeabilidade e diversidade cultural da sociedade hispano-romana.

Na região torriense os monumentos epigráficos testemunham a existência de numerosas ci//ae, em parte pertencentes à alta

(101) Alarcão, Portugal, p. 164; Mantas, p. 76-77, 86-87.

(102) Tranoy, p. 357-360; EnCarnaÇão, Épigraphie, p. 299-300.

(103) A existência de uma ou mais oficinas nesta zona é altamente provável: Mantas, p. 84-85. O uso de gentilicios abreviados pode ser uma das características de certa epigrafia da região torriense.

(104) Tranoy, p. 359. 
burguesia olisiponense (CIL II 261, 284). A densidade de ocupação parece ter sido maior na área central do concelho, certamente devido à capacidade agrícola dos solos, mas a zona litoral, com destaque para Santa Cruz de Ribamar (105), facultou igualmente vestígios da ocupação romana cuja repartição permite esboçar o traçado de uma via de comunicação em direcção à Ericeira. As inscrições da Quinta da Areia e de S. Pedro da Cadeira, locais situados perto da foz do Sizandro, rio que na Antiguidade permitia comunicar a zona em torno de Torres Vedras com o litoral (106), reforçam a carta dos estabelecimentos romanos numa região onde os contactos com o Mediterrâneo antecederam largamente o domínio romano $\left({ }^{107}\right)$, criador de uma nova dinâmica em que se inseria perfeitamente a possibilidade de, no dizer de Epicteto, «navegar de Oriente a Ocidente».

$\left(^{\circ}{ }^{5}\right)$ F Alves Pereira, Tampa de sepultura da época romana, "O Archeologo Português», XIV, 1909, p. 261-265. Também de Santa Cruz provém a inscrição do escravo Pultarius, perdida nas ruínas do convento de Penafirme (CIL II 314).

(í o6) Orlando Ribeiro, Introduções Geográficas à História de Portugal, Lisboa, 1977, p. 106.

(107) Leonel Trindade/Veiga Ferreira, Acerca do vaso "piriforme» tartéssico de bronze do Museu de Torres Vedras, «Boletim Cultural da Junta Distrital de Lisboa», 63-64, 1965, p. 175-183. 


\section{APANO/APANA: TESTEMUNHOS EPIGRÁFICOS E SUA REPARTIÇÃO}

1 - Quinta da Areia (Torres Vedras).

Apana $j$ Apanonis / f.h.s.

inédito.

2 - S. Sebastião do Freixo (Batalha).

Tongio I Apanonis / pater / im (sic) mémo

D. P. B randã o, «Conimbriga», XI, 1972, p. 121-123, n. ${ }^{\circ} 24$ (corrigida).

3 - Torre dos Namorados (Fundão). Lubaecus / Apanonis / f.h.s.e.

J. L. VAz, «Conimbriga», XVI, 1977, p. 20-21, n. ${ }^{\circ} 12$ (corrigida).

4 - Castelo Branco.

[...] I [pa]tri I Camirae / Apanonis.f. / matri J C.Ammius.Avitus $j f$

J. M. GarCia, «Conimbriga», XVIII, 1979, p. 157-160, n. ${ }^{\circ} 3$.

5 - Castelo Branco.

Lucano.an.XXX Amoenae.an.XVI.Maxijmae.an.XIII.Cilius / Boute,

pater.et Sunua / Apanonis .f.mater

J. M. Garcia, «Conimbriga», XVIII, 1979, p. 165-166, n. ${ }^{\circ} 6$.

6 - Cogula (Trancoso).

D.M.S I Apanae / Reburri f./an XVIIII / Albinus.ux / Atonius.MuJcnela.

f.f.c

J. L. vasconcelos, Religiões, III, 1913, p. 408.

7 - Hinojosa de Duero.

Apana / Bouti f. XX h. / s.s.t.t.l.

ILER 2858 .

8 - Coria.

Catueno / Tancini / f.Apana / Catueni / mater f.c.

ILER 4337.

9 - Ibahernando.

Lubaecjus Tangi/ni f.Apanfa Leuri / f.h.s.e.s.t.jt.l.Tangijnif-f.c.

ILER $3638=3915$.

10 - Puerto de la Cruz (Câceres).

Apana / Eburi / f.an.XV / h.s.e.s.t./t.l. Lancjius.Sce/vae.f.f.c

CP IL 407.

11 - Santa Cruz de la Sierra (Câceres).

Patranis.Vjegetus.h.s.e.js.t.t.l. Apana

CPIL 450.

12 - Igrejinha (Arraiolos).

Apano I Cilei.f / hic.situs e[s]t statuerunt I seror es.et.vidua

M. A. Dias, «Ficheiro Epigráfico», 2, 1982, p. 3, n. ${ }^{\circ} 11$.

Conimbriga, 24 (1985), 125-149 
ANEXo II

\section{AFRICANVS: TESTEMUNHOS EPIGRÁFICOS \\ E SUA REPARTIÇÃO}

1 - S. Pedro da Cadeira (Torres Vedras)

D[.M.S $\$ I Saturnia I an.XXV J h.s.e. / Africanus / uxori.merentissimae $j$ s.t.t.l.

Inédito.

2 - Sevilha

D.M.S ; Naevius Africanus / vixit ann.LXXV / h.s.e.s.t.t.l.

CIL II $5396=/ \mathrm{L} £ 7 ? 3391$.

3 - Córdova

Nemesi / Corneli[i] Res[ti]tutus et African[us] / exacto flamonio / votum reddiderun $[t \mid$

CIL II $2195=/$ ¿£7? 405.

4 - Denia

P.Statilius African[us an.] XlIII.m.lI.d.XIII.P.[Statilius] / Pammon pater e[t ...] / mater filio dulcis[simo pos.]

CIL II $5969=$ ILER 4074.

5 - Palencia

Annius / Atreus / Caerri / Africani / f.Duillis / v.s.l.m. ILER 804.

6 - Ujo (Oviedo) Nimmedo/sediago / G.Sulpicius / Africanus | v.s.l.m. ILER 900.

7 - Ujo (Oviedo)

G.Sulp[icio] Ursulo / praef Symmachi;ariorum Asturum / belli Dacici, leg.I 1 Minerviae P.F.jcoh.XlI Urbajnae.coh.illI / Praetoriae.p p.j leg.XIIX.praef. / leg.Ill Aug./ G.Sulp(icius) Afr(icanus).pos. ILER 5676. 


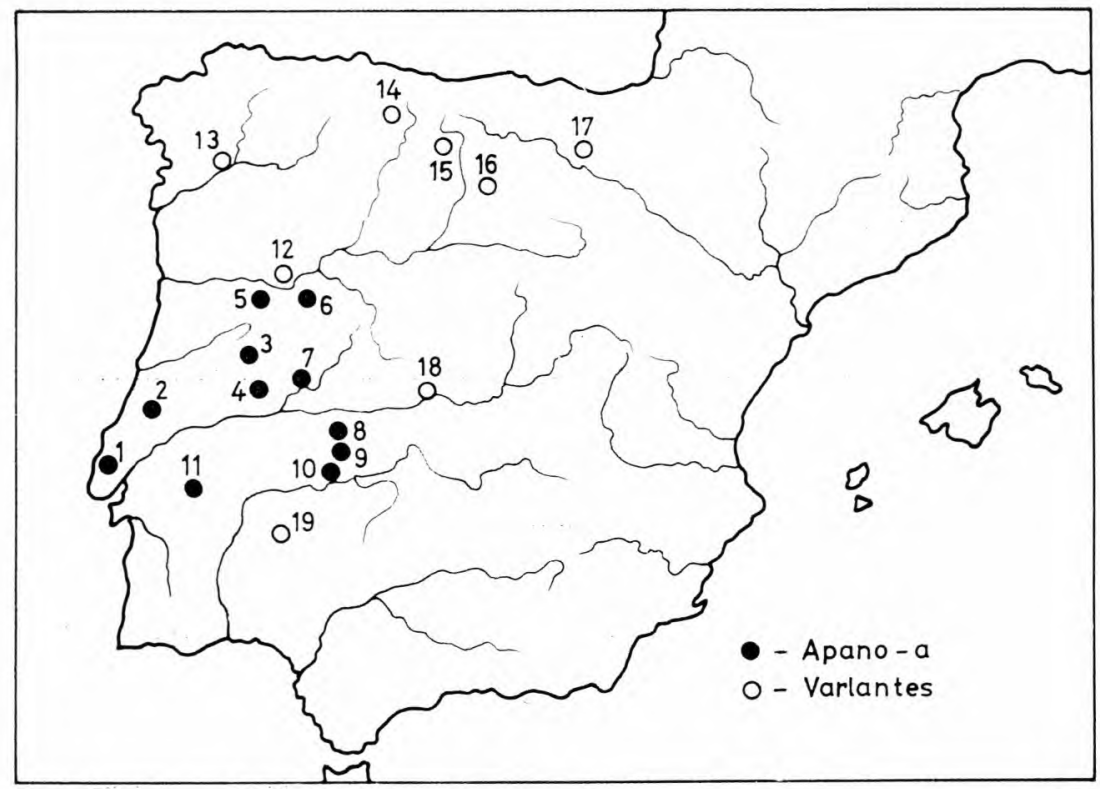

Mapa I

1 - Quinta da Areia (Torres Vedras): inédita.

2 - S. Sebastião do Freixo (Batalha): D. P. Brandão, "Conimbriga", XI, 1972, p. 121-123, n.o 24 (corrigida).

3 - Torre dos Namorados (Fundão): J. L. VAz, "Conimbriga", XVI, 1977, p. 20-21, n.o 12 (corrigida).

4 - Castelo Branco: J. M. Garcia, "Conimbriga», XVIII, 1979, p. 157-160, n. ${ }^{\circ} 3$, p. $165-166$, n. ${ }^{\circ} 6$.

5 - Cogula (Trancoso): J. L. Vasconcelos, Religiões, III, 1913, p. 408.

6- Hinojosa de Duero: ILER 2858.

7-Coria: ILER 4337.

8 - Ibahernando: ILER $3638=3915$.

9 - Puerto de la Cruz (Cáceres): CPIL 407.

10 - Santa Cruz de la Sierra (Cáceres): CPIL 450.

11 - Igrejinha (Arraiolos); M. A. Dias, "Ficheiro Epigráfico», 2, 1982, p. 3, n. ${ }^{\circ} 11$.

12 - Torre de Moncorvo: J. M. Almeida/F. B. Ferreira, "Revista de Guimarães", LXXVI, 1966, p. 346-347.

13 - Orense: $C I L$ II $2527=I L E R 619$.

14 - Valdoré: Albertos, "Emerita", XL, 1972, p. 3.

15 - Monte Bernorio (Palencia): $H A E 2253$.

16 - Sasamón: CIL II $5812=I L E R 5825$.

17 - Contrasta (Alava): CIL II 2950=ILER 2564.

18 - Talavera de la Reina: $C I L$ II 5315.

19 - Jerez de los Caballeros: CIL II 6277b. 


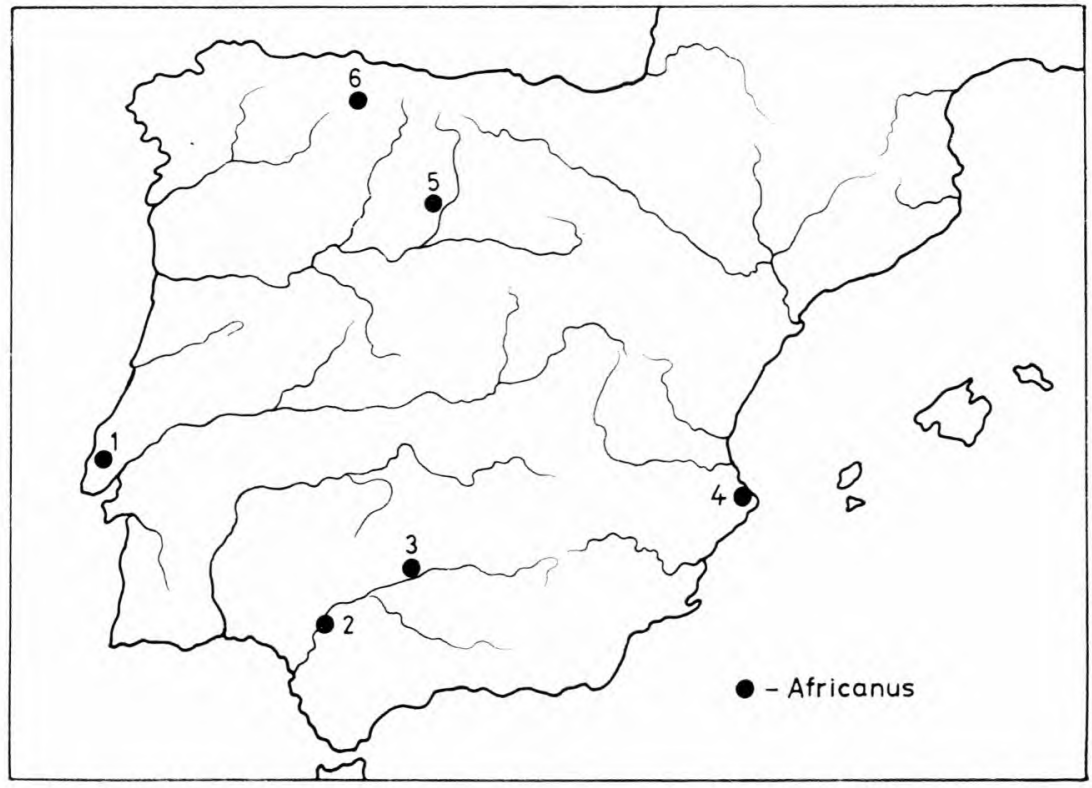

Mapa II

1 - S. Pedro da Cadeira (Torres Vedras): inédita.

2-Sevilha: CIL II 5396=ILER 3391.

3 -Córdova: CIL II 2195=ILER 405.

4-Denia: CIL II 5996 $\Rightarrow I L E R 4074$.

5 -Palencia: ILER 804.

6 - Ujo (Oviedo): ILER 900, 5676. 


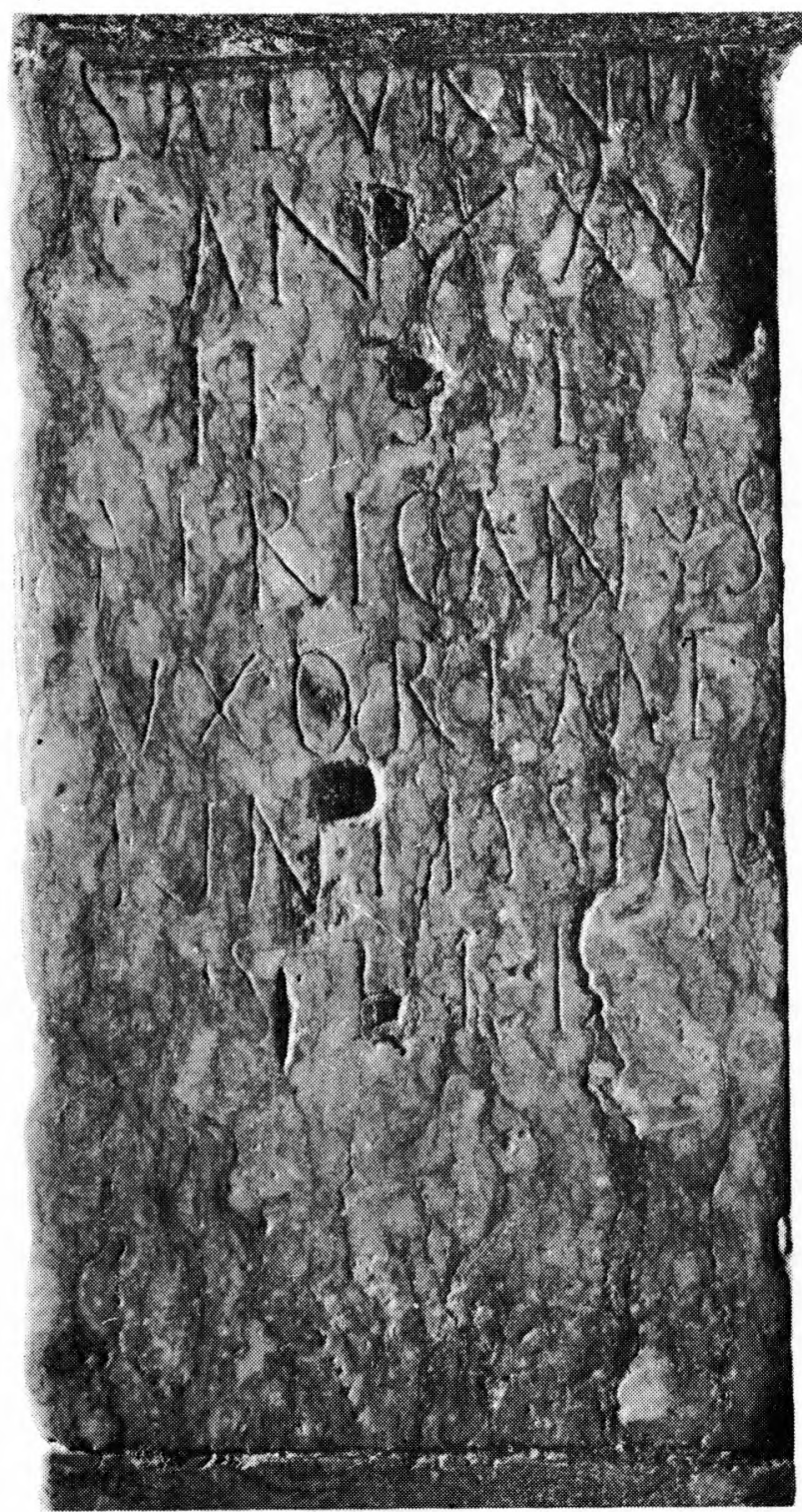

Inscrição n. ${ }^{9}$. Foto 1 


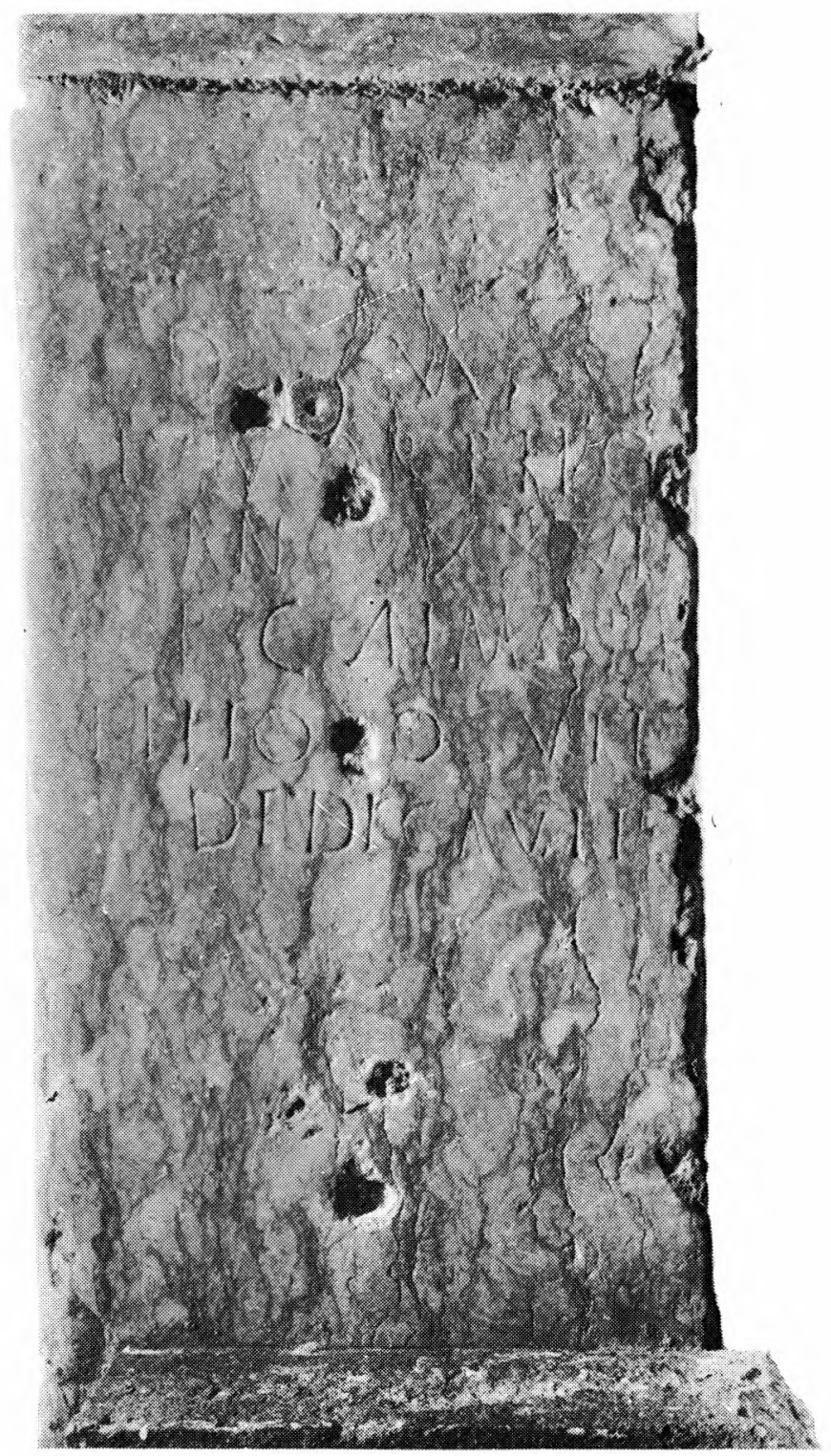

Inscrição n.o 3 . Fcto 2 